\title{
The predictive value of lymphocyte-to- monocyte ratio in the prognosis of acute coronary syndrome patients: a systematic review and meta-analysis
}

\author{
Xiao-Qing Quan ${ }^{1 \dagger}$, Run-Chang Wang ${ }^{2 \dagger}$, Qing Zhang ${ }^{3 \dagger}$, Cun-Tai Zhang ${ }^{4}$ and Lei Sun ${ }^{5^{*}}$
}

\begin{abstract}
Background: The association between the lymphocyte-to-monocyte ratio (LMR) and prognosis in the patients with acute coronary syndrome (ACS) is not fully understood. We performed this systematic review and meta-analysis to evaluate the correlation between LMR and mortality or major adverse cardiac events (MACE) in patients with ACS.

Methods: A systematic search was performed in PubMed, MEDLINE, EMBASE, the Cochrane Library, Scopus, and Web of science. The association between LMR and mortality/MACE was analyzed in patients with ACS. The search was updated to April 15, 2020

Results: A total of 5 studies comprising 4343 patients were included in this meta-analysis. The results showed that lower LMR predicted higher short-term mortality/MACE (hazard ratio [HR] $=3.44,95 \%$ confidence interval [CI]: 1.468.14, $P<0.05)$ and long-term mortality/MACE ( $\mathrm{HR}=1.70,95 \% \mathrm{Cl}: 1.36-2.13, P<0.05)$. In the subgroup analysis, there was still statistical significance of long-term mortality/MACE in all subgroups.

Conclusions: This study suggested that lower LMR value might be associated with higher short-term and longterm mortality/MACE in ACS patients. Especially for younger ACS patients, low LMR was more closely associated with poor prognosis.
\end{abstract}

Keywords: Lymphocyte-to-monocyte ratio, Mortality, Major adverse cardiac events, Acute coronary syndrome

\section{Background}

Coronary heart disease (CHD) is one of the largest causes of death and disease burden worldwide $[1,2]$. Acute coronary syndrome (ACS) is a severe category of CHD associated with a high morbidity and mortality. ACS includes unstable angina (UA), ST-segment elevation myocardial infarction (STEMI), and non-ST-segment elevation myocardial infarction (NSTEMI). Previous studies indicate

\footnotetext{
* Correspondence: leisun2011@hotmail.com

+Xiao-Qing Quan, Run-Chang Wang and Qing Zhang contributed equally to this work.

${ }^{5}$ Department of Pathology, Zhujiang Hospital, Southern Medical University, 253 Gongye Road, Guangzhou 510282, China

Full list of author information is available at the end of the article
}

that approximately half of deaths from CHD occur after ACS $[3,4]$. Rupture of atherosclerotic plaques and formation of thrombi are the main cause of ACS [5-7]. The atherosclerotic plaques are associated with the infiltration of inflammatory cells (lymphocytes, monocytes, and neutrophils) [8-10]. Inflammation plays a critical role in initiation, progression, and rupture of atherosclerotic plaque in ACS patients $[9,10]$.

Markers of inflammation are associated with the prognosis of patients with ACS. The neutrophil-to-lymphocyte ratio (NLR) has been established as a valuable predictor of the prognosis of ACS [11-13]. Compared with neutrophils, monocytes play a more important role in the

(c) The Author(s). 2020 Open Access This article is licensed under a Creative Commons Attribution 4.0 International License, which permits use, sharing, adaptation, distribution and reproduction in any medium or format, as long as you give appropriate credit to the original author(s) and the source, provide a link to the Creative Commons licence, and indicate if changes were made. The images or other third party material in this article are included in the article's Creative Commons licence, unless indicated otherwise in a credit line to the material. If material is not included in the article's Creative Commons licence and your intended use is not permitted by statutory regulation or exceeds the permitted use, you will need to obtain permission directly from the copyright holder. To view a copy of this licence, visit http://creativecommons.org/licenses/by/4.0/. The Creative Commons Public Domain Dedication waiver (http://creativecommons.org/publicdomain/zero/1.0/) applies to the data made available in this article, unless otherwise stated in a credit line to the data. 
pathogenesis of atherosclerotic disease [14]. The role of monocyte infiltration of the arterial wall in the development of atherosclerotic plaques is well recognized [15]. In addition, previous studies have showed that monocytes are associated with the onset of myocardial infarction (MI) and left ventricular remodeling [16, 17].

In recent years, a growing body of research has focused on the relationship between lymphocyte-tomonocyte ratios (LMR) and mortality or major adverse cardiac events (MACE) in patients with ACS. However, the conclusions of these studies are controversial. For example, Gijsberts et al. indicated that LMR significantly improved prediction of mortality [18]. In the latter study, Kristono et al. found that LMR is not enough to be used for prediction in a clinical setting [19]. Herein, we performed this meta-analysis to explore the predictive value of LMR in ACS patients.

\section{Methods}

This meta-analysis was performed followed the Preferred Reporting Items of Systematic Reviews and MetaAnalyses (PRISMA) statement. We registered this metaanalysis in the PROSPERO database (CRD42019131296).

\section{Search strategy}

A systematic literature search was conducted in PubMed, MEDLINE, EMBASE, the Cochrane Library, Scopus, and Web of science. We used the following terms to search literature: "STEMI" "UA", "NSTEMI", "lymphocyte to monocyte ratio", "lymphocyte-to-monocyte ratio", "lymphocyte/monocyte ratio", "monocyte/ lymphocyte ratio", "mortality", "MACE" and "major adverse cardiac events". The latest update was performed in April 15, 2020. We also screened the reference lists of all retrieved articles to identify other potentially relevant literature.

\section{Inclusion and exclusion criteria}

Studies were included if they met all the following criteria: (1) articles were published as full-text in English; (2) patients with ACS (STEMI, UA, NSTEMI); (3) LMR (hazard ratio $[\mathrm{HR}], 95 \%$ confidence interval [CI]) was available; (4) the outcomes were associated with mortality or MACE. Articles were excluded if they met any of the following characteristics: (1) nonhuman studies; (2) duplicate studies; (3) absence of LMR or mortality/ MACE. Two investigators (Xiao-Qing Quan and RunChang Wang) read the literature independently of each other. Disagreements solved by discussion with other investigators.

\section{Data extraction and quality assessment}

The following data were extracted: the first author, the country of patients, duration, the mean age, sample size of patients, LMR cut-off value, diseases of patients, HRs and $95 \%$ CIs and outcomes. The outcomes of studies included mortality (all-cause mortality) and MACE (including stroke/transient ischemic attack, target vessel revascularization, non-fatal MI, and cardiac death). The methodological quality of each study was evaluated with Newcastle-Ottawa Scale (NOS) system [20]. The maximum score is 9 and the study with a NOS score $\geq 6$ was considered as a high-quality study.

\section{Statistical analysis}

All statistical analyses in the present study were conducted with STATA statistical software (version 13.1, Stata Corporation, College Station, TX, USA). We synthesized the HR and corresponding 95\% CI to analysis of the relationship between LMR and mortality/MACCE. Between-study heterogeneity was assessed using Cochrane's $Q$ and $\mathrm{I}^{2}$ texts. $\mathrm{I}^{2}<25 \%$ was regarded as low levels of heterogeneity. $\mathrm{I}^{2}$ value of 25 to $50 \%$ was regarded as moderate levels of heterogeneity. $\mathrm{I}^{2}>50 \%$ was regarded as high levels of heterogeneity. A fixed-effects model was applied in the absence of significant heterogeneity $\left(\mathrm{I}^{2} \leq 50 \%\right)$, or the random effect model was applied $\left(\mathrm{I}^{2}>50 \%\right)$.

\section{Results}

The literature search and include studies

A flowchart of the literature search was shown in Fig. 1. Initially, in the primary search from the major databases, a total of 741 studies were included. After removing duplicates and screening titles and abstracts, a total of 154 papers remained, but 138 of them did not meet our purpose. The remaining 16 articles were assessed for eligibility based on full-text review, 11 were deemed ineligible. After qualitative and quantitative analysis, according to the inclusion criteria, only 5 studies published from 2016 to 2019 were selected for our meta-analysis [18, 21-24].

Basic characteristics of the included studies were listed in Table 1. A total of 4343 patients were included. These studies were all observation researchers and one conducted in Netherlands [18], one conducted in Turkey [21], three conducted in China [2224]. The mean age of the patients ranges from 60.77 to 65.12 years old. Two studies in this meta-analysis enrolled STEMI patients [21, 24]. Two studies enrolled NSTEMI patients [22, 23], and the remaining one study enrolled ACS patients [18]. Two of studies explicitly stated that the patients underwent PCI [21, $22]$, while others did not specify if enrolled patients underwent PCI $[18,23,24]$. Two studies reported the mortality $[18,21]$, and three studies reported MACE [22-24]. All the studies have reported adjusted HR values. Adjusted confounding factors of each study were shown in Table 2. According to the Newcastle- 

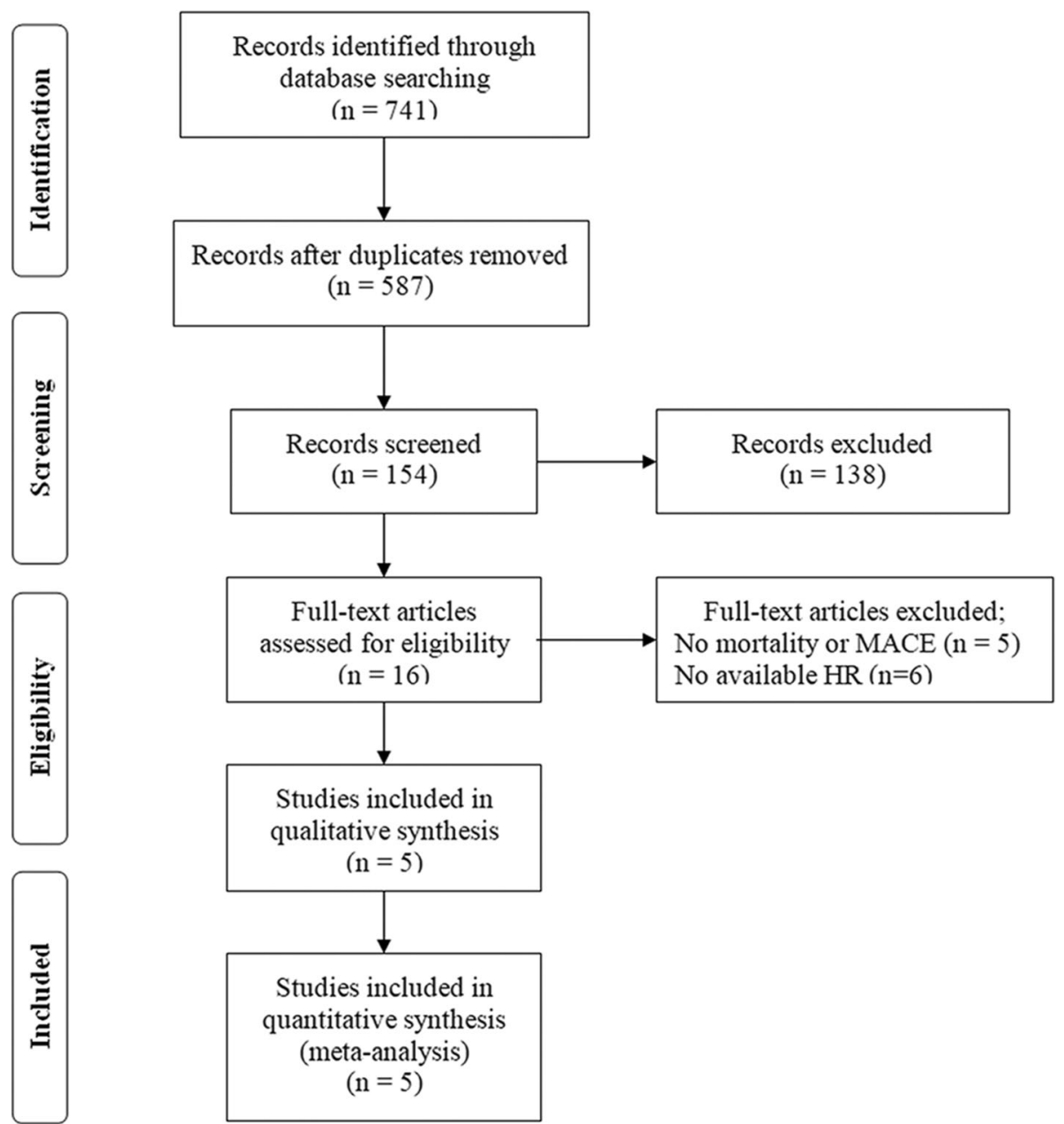

Fig. 1 PRISMA flowchart describing the literature search and article selection

Ottawa scale (NOS) [20], all cohort studies were of high quality and had scores of seven or more.

\section{LMR and mortality/MACE}

The short-term was defined as within 30 days after admission to hospital. If the hospitalization lasted more than 30 days, the excess was also included. Others were defined as long-term. The combined analysis of 2 studies covering 1281 patients described the relationship between LMR and short-term mortality/MACE [21, 23]. The result showed that LMR predicted short-term mortality/MACE $(\mathrm{HR}=3.44,95 \% \mathrm{CI}: 1.46-8.14, P<0.05$, Fig. 2a), with low levels of heterogeneity among studies $\left(\mathrm{I}^{2}=0 \%\right)$. The combined analysis of 5 studies covering

Table 1 The main characteristics of the included studies

\begin{tabular}{|c|c|c|c|c|c|c|c|c|}
\hline Study (year) & Country & Duration & $\begin{array}{l}\text { Mean Age } \\
\text { (years) }\end{array}$ & LMR cut-off value & Patient's diseases & Sample & Outcomes & Quality (NOS) \\
\hline Gijsberts CM (2016) [18] & Netherlands & 2010-2013 & 65.12 & 3.11 & ACS & 1015 & Long-term mortality & 8 \\
\hline Kiris T (2017) [21] & Turkey & 2010-2013 & 61.5 & 1.67 & STEMI & 318 & $\begin{array}{l}\text { 30-day mortality } \\
\text { 36-month mortality }\end{array}$ & 7 \\
\hline Fan Z (2018) [22] & China & 2010-2015 & 62.34 & 2.78 & NSTEMI & 678 & Long-term MACE & 7 \\
\hline Cheng H (2019) [23] & China & 2013-2017 & 60.77 & 2.33 & NSTEMI & 963 & $\begin{array}{l}\text { In-hospital MACE } \\
\text { Long-term MACE }\end{array}$ & 8 \\
\hline Cai M (2019) [24] & China & 2014-2017 & 63.08 & 1.84 & STEMI & 1369 & Long-term MACE & 8 \\
\hline
\end{tabular}


Table $2 \mathrm{HR}$ and adjusted confounding factors of included studies

\begin{tabular}{|c|c|c|c|}
\hline Study (year) & Outcomes & $\mathrm{HR}(95 \% \mathrm{Cl})$ & Adjusted confounding factors \\
\hline $\begin{array}{l}\text { Gijsberts CM } \\
\text { (2016) [18] }\end{array}$ & $\begin{array}{l}\text { Long-term } \\
\text { mortality }\end{array}$ & $\begin{array}{l}1.35(1.14- \\
1.59)\end{array}$ & Leukocyte characteristics (lymphocyte cell size coefficient of variation, monocyte count) \\
\hline $\begin{array}{l}\text { Kiris T (2017) } \\
{[21]}\end{array}$ & $\begin{array}{l}\text { 30-day } \\
\text { mortality } \\
\text { 36-month } \\
\text { mortality }\end{array}$ & $\begin{array}{l}8.093(1.006- \\
65.074) \\
2.374(1.160- \\
4.857)\end{array}$ & $\begin{array}{l}\text { Age, gender, history of stroke/TIA, history of DM, multivessel disease, Killip, albumin, LVEF, } \\
\text { hemoglobin, RDW, MPV, serum creatinine, total bilirubin, } \beta \text {-blocker usage, ACEI/ARB usage }\end{array}$ \\
\hline $\begin{array}{l}\text { Fan Z (2018) } \\
{[22]}\end{array}$ & $\begin{array}{l}\text { Long-term } \\
\text { MACE }\end{array}$ & $\begin{array}{l}2.128(1.458- \\
3.105)\end{array}$ & NLR, hs-CRP, brain natriuretic peptide \\
\hline $\begin{array}{l}\text { Cheng H (2019) } \\
{[23]}\end{array}$ & $\begin{array}{l}\text { In-hospital } \\
\text { MACE } \\
\text { Long-term } \\
\text { MACE }\end{array}$ & $\begin{array}{l}2.891(1.265- \\
8.354) \\
1.793(1.169- \\
2.515)\end{array}$ & $\begin{array}{l}\text { Age, male, body mass index, hypertension, DM, dyslipidemia, history of coronary artery disease, } \\
\text { history of myocardial infarction, smoking index, Leukocyte, NLR, hs-CRP, gensini score }\end{array}$ \\
\hline $\begin{array}{l}\text { Cai M (2019) } \\
{[24]}\end{array}$ & $\begin{array}{l}\text { Long-term } \\
\text { MACE }\end{array}$ & $\begin{array}{l}1.74(1.12- \\
2.70)\end{array}$ & $\begin{array}{l}\text { Age, sex, Killip, DM, hypertension, hyperlipidemia, PCI, } \beta \text {-blocker usage, ACEI/ARB usage, glucose, } \\
\text { white blood cell, hemoglobin, In CK-peak, MPV, RDW, LVEF, location of myocardial infarction }\end{array}$ \\
\hline
\end{tabular}

Abbreviations: ACEl angiotensin-converting enzyme inhibitors, $A R B$ angiotensin receptor blockers, $C l$ confidence interval, DM diabetes mellitus, HR hazard ratio, $h s-$ $C R P$ high-sensitivity C reactive protein, $L V E F$ left ventricular ejection fraction, MPV mean platelet volume, NLR neutrophil-to-lymphocyte ratio, $P C l$ percutaneous coronary intervention, RDW red cell distribution width, TIA transient ischemic attack

4343 patients described the relationship between LMR and long-term mortality/MACE [18, 21-24]. The pooled outcome for low LMR value compared with high LMR value group was found to be 1.70 (95\% CI: 1.36-2.13, $P<0.05$, Fig. $2 \mathrm{~b}$ ), with moderate levels of heterogeneity among studies $\left(\mathrm{I}^{2}=46.8 \%\right)$.

\section{Subgroup analysis}

There were moderate levels of heterogeneity $\left(\mathrm{I}^{2}=46.8 \%\right)$ in the analysis of LMR predicting long-term mortality/ MACE. We performed subgroup analysis according to mean age ( $\geq 62$ and $<62$ ), LMR cut-off value ( $\geq 2$ and $<$ $2)$, sample size $(\geq 1000$ and $<1000)$ and diseases of

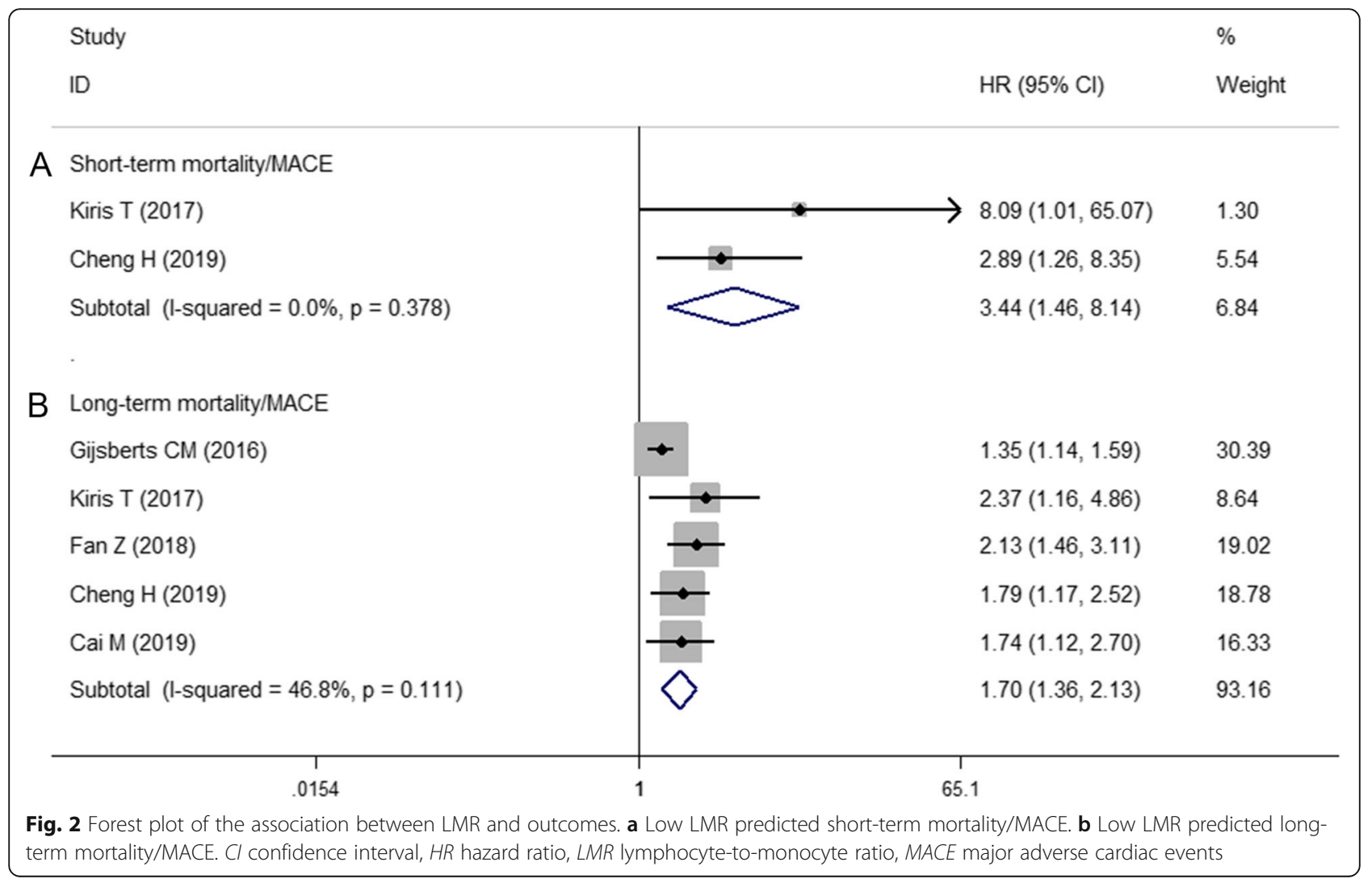


patients (ACS, STEMI and NSTEMI). The results were shown in Table 3. Compared with older ACS patients ( $\geq$ 62), LMR had better predictive value of long-term mortality/MACE in younger ACS patients $(<62)$. And low LMR predicted long-term mortality/MACE showed a statistical significance in any subgroup. Based on the change of $\mathrm{I}^{2}$, the sources of heterogeneity might be mean age of enrolled patients and defined cut-off value (Table $3)$. In the subgroup of older $(\geq 62)$ ACS patients, $I^{2}$ increased to $61.8 \%$. In the subgroup of higher $(\geq 2)$ LMR cut-off value, $\mathrm{I}^{2}$ increased to $64.7 \%$.

\section{Discussion}

ACS has a high morbidity and remains one of the major causes of mortality in the world [3, 4]. Previous studies have suggested that LMR may be associated with the prognosis of ACS patients [21-23, 25, 26]. Here we performed this meta-analysis to analyze the relationship between LMR and the prognosis of ACS patients. The aggregated results showed that a lower LMR might predict a higher mortality/MACE in patients with ACS.

In this meta-analysis, we enrolled 5 studies comprising 4343 patients to investigate the prognostic value of the LMR in patients with ACS [18, 21-24]. The present study showed that LMR might be a predictor for shortterm mortality/MACE. However, only two studies examined the effect of LMR on short-term mortality/MACE. More related studies are needed to explore the predictive value of low LMR for short-term mortality.

Results from the present study suggested that lower LMR was associated with higher long-term mortality/ MACE in patients with ACS. Because there was a moderate level of heterogeneity among studies, we conducted subgroup analysis to further analyze the results. In all

Table 3 The association between LMR and long-term mortality/ MACE according to different subgroups

\begin{tabular}{|c|c|c|c|c|c|}
\hline Subgroup & Study (No.) & $1^{2}(\%)$ & $P\left(I^{2}\right)$ & $\operatorname{HR}(95 \% \mathrm{Cl})$ & $P(H R)$ \\
\hline \multicolumn{6}{|l|}{ Mean Age } \\
\hline$\geq 62$ & 3 & 61.8 & 0.073 & $1.64(1.22,2.21)$ & $<0.001$ \\
\hline$<62$ & 2 & 0 & 0.498 & $1.91(1.36,2.68)$ & $<0.001$ \\
\hline \multicolumn{6}{|c|}{ Cut-off value } \\
\hline$\geq 2$ & 3 & 64.7 & 0.059 & $1.66(1.24,2.23)$ & $<0.001$ \\
\hline$<2$ & 2 & 0 & 0.469 & $1.89(1.30,2.76)$ & $<0.001$ \\
\hline \multicolumn{6}{|l|}{ Sample } \\
\hline$\geq 1000$ & 2 & 10.6 & 0.290 & $1.41(1.17,1.69)$ & $<0.001$ \\
\hline$<1000$ & 3 & 0 & 0.728 & $2.00(1.56,2.58)$ & $<0.001$ \\
\hline \multicolumn{6}{|l|}{ Disease } \\
\hline ACS & 1 & NA & NA & $1.35(1.14,1.59)$ & $<0.001$ \\
\hline STEMI & 2 & 0 & 0.469 & $1.89(1.30,2.76)$ & $<0.001$ \\
\hline NSTEMI & 2 & 0 & 0.533 & $1.96(1.49,2.54)$ & $<0.001$ \\
\hline
\end{tabular}

subgroups, LMR still had predictive value for poor prognosis, which indicated that the results were relatively reliable. Meanwhile, we found that mean age and defined cut-off value might be the sources of heterogeneity. We hypothesized that older ACS patients had more complex factors affecting the prognosis, such as immune status and nutritional status, leading to higher inter-study heterogeneity. And higher cut-off value had worse predictive value for poor prognosis. This might be the reason that heterogeneity occurred among studies with higher cut-off value. Our results also showed that low LMR was valuable for predicting poor prognosis in STEMI and NSTEMI patients, which was consistent with previous researches [21-24].

ACS is related to atherosclerosis, which is accompanied by the infiltration of inflammatory cells [8-10]. Lymphocytes and monocytes are pivotal immune cells and play an important role in inflammatory response and atherosclerosis development [27, 28]. Previous studies indicated that decreased lymphocytes and increased monocytes might be related to the poor prognosis of the MI patients [29-31].. Lymphocytes might be driven by recognition of cardiac auto antigens, became activated after MI, and facilitated the healing of the myocardium [29]. MI could activate adrenergic signaling and trigger the production of monocytes. Excessive mononuclear growth might impair myocardial healing and exacerbate cardiovascular complications [30,31]. The above results indicated that lymphocyte and monocyte might be related to the prognosis of the MI patients.

Our studies had some limitations. Firstly, we did subgroup analysis and identified possible sources of heterogeneity. We could not accurately locate heterogeneity because of the subgroup analysis was observational. Secondly, only five studies were included in the metaanalysis, potentially leading to heterogeneity and less persuasive. Thirdly, all the enrolled studies were observational researchers. Compared with experimental studies, observational studies are more likely to have the risk of bias, which also relatively influence the accuracy of the study.

To the best of our knowledge, this is the first metaanalysis addressing the relationship between LMR and the mortality/MACE in patients with ACS. This metaanalysis showed that LMR could be a valuable predictor in predicting mortality/MACE in patients with ACS. What's more, in many primary hospitals, routine blood is the most rapid and basic detection methods which can immediately determine the patient's condition. LMR might be used as an inexpensive and useful marker in assessment of patients with ACS.

\section{Conclusions}

In summary, this meta-analysis showed that a low LMR value might be effective in predicting the risk of short- 
term and long-term mortality/MACE in patients with ACS. Especially for younger ACS patients, a low LMR value might be more effective in predicting poor prognosis. But additional research was required to verify its effectiveness.

\begin{abstract}
Abbreviations
LMR: Lymphocyte-to-monocyte ratio; CHD: Coronary heart disease; ACS: Acute coronary syndrome; MACE: Major adverse cardiac events; HR: Hazard ratio; Cl: Confidence interval; STEMI: ST-elevated myocardial infarction; UA: Unstable angina; NSTEMI: Non-ST-segment elevation myocardial infarction; NLR: Neutrophil-to-lymphocyte ratio; MI: Myocardial infarction; PRISMA: Preferred reporting items of systematic reviews and metaanalyses; NOS: Newcastle-Ottawa scale; PCl: Percutaneous coronary intervention; TIA: Transient ischemic attack; DM: Diabetes mellitus; LVEF: Left ventricular ejection fraction; RDW: Red cell distribution width; MPV: Mean platelet volume; ACEl: Angiotensin-converting enzyme inhibitors; ARB: Angiotensin receptor blockers; hs-CRP: High-sensitivity $C$ reactive protein
\end{abstract}

\section{Acknowledgments}

Not applicable.

\section{Authors' contributions}

XQQ, RCW and QZ contributed to the study design, the data acquisition, analysis, interpretation, the drafting, and revision of the manuscript and agreed to be accountable for all aspects of the work. CTZ contributed to the study conceive, the supervision, data interpretation, and performed revision of the manuscript. LS contributed to the study conceive, design, data analysis, interpretation, and revised the manuscript. All authors read and approved the final manuscript

\section{Funding}

This work is supported by the grants from Shenzhen Key Medical Discipline Construction Fund (SZXK063) and the National Natural Science Foundation of China (81400255), hosted by Xiao-Qing Quan. The fund mainly provides research funding support but has no role in the study design, the data acquisition, analysis, interpretation, the drafting, and revision of the manuscript.

\section{Availability of data and materials}

Because this is a meta-analysis, all of data included in this study could be found in the included references.

\section{Ethics approval and consent to participate}

Not applicable.

\section{Consent for publication}

Not applicable.

\section{Competing interests}

The authors declare that they have no competing interests.

\section{Author details}

'Department of General Practice, Shenzhen Longhua District Central Hospital, Shenzhen 518110, China. ${ }^{2}$ Second clinical medical college, Tongji Medical College, Huazhong University of Science and Technology, Wuhan 430030, China. ${ }^{3}$ Department of Neurology, Tongji Hospital, Tongji Medical College, Huazhong University of Science and Technology, Wuhan 430030, China. ${ }^{4}$ Department of Geriatrics, Tongji Hospital, Tongji Medical College, Huazhong University of Science and Technology, Wuhan 430030, China. ${ }^{5}$ Department of Pathology, Zhujiang Hospital, Southern Medical University, 253 Gongye Road, Guangzhou 510282, China.

Received: 3 September 2019 Accepted: 6 July 2020

Published online: 15 July 2020

\section{References}

1. Gaziano TA, Bitton A, Anand S, Abrahams-Gessel S, Murphy A. Growing epidemic of coronary heart disease in low- and middle-income countries. Curr Probl Cardiol. 2010;35:72-115.
2. Wang F, Zhang LY, Zhang P, Cheng Y, Ye BZ, He MA, et al. Effect of physical activity on hospital service use and expenditures of patients with coronary heart disease: results from Dongfeng-Tongji cohort study in China. Curr Med Sci. 2019:39:483-92.

3. Makki N, Brennan TM, Girotra S. Acute coronary syndrome. J Intensive Care Med. 2015;30:186-200

4. Li SJ, Barywani S, Fu M. Relationship between physical inactivity and longterm outcome in patients aged $>=80$ years with acute coronary syndrome. Curr Med Sci. 2018:38:64-9.

5. Dalen JE, Alpert JS, Goldberg RJ, Weinstein RS. The epidemic of the 20(th) century. Coronary heart disease. Am J Med. 2014;127:807-12.

6. Ding S, Lin N, Sheng X, Zhao Y, Su Y, Xu L, et al. Melatonin stabilizes rupture-prone vulnerable plaques via regulating macrophage polarization in a nuclear circadian receptor RORalpha-dependent manner. J Pineal Res. 2019;67:e12581.

7. Wang Y, Sun X, Xia B, Le C, Li Z, Wang J, et al. The role of OX40L and ICAM1 in the stability of coronary atherosclerotic plaques and their relationship with sudden coronary death. BMC Cardiovasc Disord. 2019;19:272.

8. Libby P. Inflammation in atherosclerosis. Arterioscler Thromb Vasc Biol. 2012; 32:2045-51

9. Libby P, Ridker PM, Hansson GK. Leducq transatlantic network on a. inflammation in atherosclerosis: from pathophysiology to practice. J Am Coll Cardiol. 2009:54:2129-38.

10. Pant S, Deshmukh A, Gurumurthy GS, Pothineni NV, Watts TE, Romeo F, et al. Inflammation and atherosclerosis--revisited. J Cardiovasc Pharmacol Ther. 2014;19:170-8

11. Chen J, Chen MH, Li S, Guo YL, Zhu CG, Xu RX, et al. Usefulness of the neutrophil-to-lymphocyte ratio in predicting the severity of coronary artery disease: a Gensini score assessment. J Atheroscler Thromb. 2014;21:1271-82.

12. Kaya MG, Akpek M, Lam YY, Yarlioglues M, Celik T, Gunebakmaz O, et al. Prognostic value of neutrophil/lymphocyte ratio in patients with STelevated myocardial infarction undergoing primary coronary intervention: a prospective, multicenter study. Int J Cardiol. 2013;168:1154-9.

13. Guo TM, Cheng B, Ke L, Guan SM, Qi BL, Li WZ, et al. Prognostic value of neutrophil to lymphocyte ratio for in-hospital mortality in elderly patients with acute myocardial infarction. Curr Med Sci. 2018:38:354-9.

14. Woollard K, Geissmann F. Monocytes in atherosclerosis: subsets and functions. Nat Rev Cardiol. 2010;7:77-86.

15. Santos-Gallego CG, Picatoste B, Badimon JJ. Pathophysiology of acute coronary syndrome. Curr Atheroscler Rep. 2014;16:401.

16. Eskandarian R, Ghorbani R, Asgary Z. Relationship between leucocytosis and left ventricular ejection fraction in patients with acute myocardial infarction. Singap Med J. 2013;54:40-3.

17. Maekawa Y, Anzai T, Yoshikawa T, Asakura Y, Takahashi T, Ishikawa S, et al. Prognostic significance of peripheral monocytosis after reperfused acute myocardial infarction:a possible role for left ventricular remodeling. J Am Coll Cardiol. 2002:39:241-6.

18. Gijsberts CM, Ellenbroek GH, Ten Berg MJ, Huisman A, van Solinge WW, Asselbergs FW, et al. Routinely analyzed leukocyte characteristics improve prediction of mortality after coronary angiography. Eur J Prev Cardiol. 2016; 23:1211-20

19. Kristono GA, Holley AS, Harding SA, Larsen PD. White blood cell subtypes as predictors of adverse cardiac events. Coron Artery Dis. 2020;31:446-50.

20. Stang A. Critical evaluation of the Newcastle-Ottawa scale for the assessment of the quality of nonrandomized studies in meta-analyses. Eur J Epidemiol. 2010;25:603-5.

21. Kiris T, Celik A, Varis E, Akan E, Akyildiz ZI, Karaca M, et al. Association of Lymphocyte-to-Monocyte Ratio with the mortality in patients with STelevation myocardial infarction who underwent primary percutaneous coronary intervention. Angiology. 2017;68:707-15.

22. Fan $Z$, Li Y, Ji H, Jian X. Prognostic utility of the combination of monocyteto-lymphocyte ratio and neutrophil-to-lymphocyte ratio in patients with NSTEMl after primary percutaneous coronary intervention: a retrospective cohort study. BMJ Open. 2018:8:e023459.

23. Chen H, Li M, Liu L, Dang XW, Zhu DJ, Tian G. Monocyte/lymphocyte ratio is related to the severity of coronary artery disease and clinical outcome in patients with non-ST-elevation myocardial infarction. Medicine. 2019;98:e16267.

24. Cai M, Liang D, Gao F, Hong X, Feng X, Yang Y, et al. Association of lymphocyte-to-monocyte ratio with the long-term outcome after hospital discharge in patients with ST-elevation myocardial infarction: a retrospective cohort study. Coron Artery Dis. 2020;31:248-54. 
25. Wang Q, Ma J, Jiang Z, Wu F, Ping J, Ming L. Association of lymphocyte-tomonocyte ratio with in-hospital and long-term major adverse cardiac and cerebrovascular events in patients with ST-elevated myocardial infarction. Medicine. 2017:96:e7897.

26. Kurtul A, Yarlioglues M, Celik IE, Duran M, Elcik D, Kilic A, et al. Association of lymphocyte-to-monocyte ratio with the no-reflow phenomenon in patients who underwent a primary percutaneous coronary intervention for STelevation myocardial infarction. Coron Artery Dis. 2015;26:706-12.

27. Camici PG, Rimoldi OE, Gaemperli O, Libby P. Non-invasive anatomic and functional imaging of vascular inflammation and unstable plaque. Eur Heart J. 2012:33:1309-U1329.

28. Hofmann U, Frantz S. Role of lymphocytes in myocardial injury, healing, and remodeling after myocardial infarction. Circ Res. 2015;116:354-67.

29. Hofmann U, Beyersdorf N, Weirather J, Podolskaya A, Bauersachs J, Ertl G, et al. Activation of CD4+ T lymphocytes improves wound healing and survival after experimental myocardial infarction in mice. Circulation. 2012; 125:1652-63.

30. Ruparelia N, Godec J, Lee R, Chai JT, Dall'Armellina E, McAndrew D, et al. Acute myocardial infarction activates distinct inflammation and proliferation pathways in circulating monocytes, prior to recruitment, and identified through conserved transcriptional responses in mice and humans. Eur Heart J. 2015:36:1923-34.

31. Dutta P, Nahrendorf M. Monocytes in myocardial infarction. Arterioscler Thromb Vasc Biol. 2015;35:1066-70.

\section{Publisher's Note}

Springer Nature remains neutral with regard to jurisdictional claims in published maps and institutional affiliations.

Ready to submit your research? Choose BMC and benefit from:

- fast, convenient online submission

- thorough peer review by experienced researchers in your field

- rapid publication on acceptance

- support for research data, including large and complex data types

- gold Open Access which fosters wider collaboration and increased citations

- maximum visibility for your research: over $100 \mathrm{M}$ website views per year

At $\mathrm{BMC}$, research is always in progress.

Learn more biomedcentral.com/submissions 